\title{
EVALUATION OF LAPAROSCOPIC VERSUS OPEN SURGERY FOR COLORECTAL MALIGNANCY: A SINGLE INSTITUTE STUDY
}

\author{
Vikas Warikoo', Abhishek Jain², Amit Chakraborty33, Ramesh Kumar ${ }^{4}$ \\ ${ }^{1}$ Assistant Professor, Department of Surgical Oncology, GCRI, Ahmedabad. \\ ${ }^{2}$ Assistant Professor, Department of Surgical Oncology, GCRI, Ahmedabad. \\ ${ }^{3}$ Resident Surgical, Department of Oncology, GCRI, Ahmedabad. \\ ${ }^{4}$ Resident Surgical, Department of Oncology, GCRI, Ahmedabad.
}

\section{ABSTRACT}

\section{BACKGROUND}

Colorectal cancer is a significant leading cause of death from malignancy related deaths. Surgery is the mainstay of the trea tment combined with chemotherapy, radiotherapy or both. The oncological outcomes of laparoscopic surgery have been shown to be similar to open surgery with benefits of laparoscopic colorectal surgery seen in terms of fewer complications and shorter hospital stay.

\section{MATERIALS AND METHODS}

From August 2011 to August 2016, 304 patients with colorectal malignancy undergoing surgery were included in the study, out of which 104 (34\%) underwent laparoscopic procedure and 200 (66\%) underwent open surgery. Both types of surgeries were performed by surgeons with similar expertise and experience in a single institute to make comparison and conclusions valid.

\section{RESULTS}

Total 3044 patients observed during this period divided into 2 groups, Laparoscopic Group (LG) with 104 (34\%) and to open colorectal (OG) with $200(66 \%)$ patients.

\section{CONCLUSION}

Laparoscopic colorectal surgery results have been shown to be similar in safety and oncological adequacy and completeness of the resection compared to open procedure with benefit of reduction in the morbidity, hospital stay, returns to normal daily activities, lesser blood loss and analgesia requirement. These favourable findings of laparoscopic resection for colorectal malignancy warrant further longer follow-up and results of prospectively randomised studies.

\section{KEYWORDS}

Laparoscopy, Colorectal Surgery, Colon, Rectum, Malignancy.

HOW TO CITE THIS ARTICLE: Warikoo V, Jain A, Chakraborty A, et al. Evaluation of laparoscopic versus open surgery for colorectal malignancy: a single institute study. J. Evolution Med. Dent. Sci. 2016;5(83):6213-6217, DOI: 10.14260/jemds/2016/1403

\section{BACKGROUND}

Colorectal cancer remains the third most common cancer diagnosed and the third most common cause of cancer death in both sexes in industrialised nations. ${ }^{1}$ About $90-92 \%$ and $84 \%$ of patients with cancer of colon and rectum, respectively, are treated surgically. ${ }^{2}$ Conventional open surgery is associated with significant morbidity and long convalescence. The benefits of laparoscopic colorectal surgery are seen in terms of reduced blood loss, less postoperative pain, better pulmonary function, faster return of bowel function, fewer complications and shorter hospital stay. ${ }^{3}$ However, despite the theoretical short-term advantages and equivalent cancer outcomes, adoption rates of laparoscopic colorectal surgery remain low. Laparoscopic colorectal surgery is technically complex, as it involves laparoscopic mobilisation of colon over

Financial or Other, Competing Interest: None.

Submission 23-09-2016, Peer Review 09-10-2016,

Acceptance 11-10-2016, Published 17-10-2016.

Corresponding Author:

Dr. Amit Chakraborty,

GCS Hostel, Chamunda Bridge,

Ahmedabad-380004.

E-mail: ilovepast@gmail.com

DOI: $10.14260 / \mathrm{jemds} / 2016 / 1403$ a wide area, intracorporeal division of major vessels, extraction of specimen and a bowel anastomosis. There is a steep learning curve to achieve advanced laparoscopic skills and specialised equipment is required. There are concerns with oncological outcome and safety of the laparoscopic procedure in colorectal cancer. There are also controversies with potential port site recurrence 4 after curative resection. This study is an attempt to evaluate and compare the role of laparoscopy in colorectal surgery versus open colorectal surgery as role of laparoscopy is rapidly emerging as a standard modality to approach these patients.

\section{OBJECTIVE}

To assess the safety, post-operative short-term morbidity and efficacy of Laparoscopic colorectal surgery for cancer as compared with open surgery.

To study adequacy of oncological resection with regard to proximal, distal and circumferential resection margins in both Open and Laparoscopic colorectal surgery.

\section{METHODOLOGY}

In this study, we wish to compare the outcome of laparoscopic and open colorectal surgery in a contemporary series of patients from a single institute. All procedures were undertaken in an Institute, which has high volume of patients with colorectal cancer. We wish to compare laparoscopic 
approach to open approach performed by surgeons with same expertise and experience in a single institute to make comparison and conclusion valid.

This study includes all patients who underwent laparoscopic colorectal surgery in all the units of hospital during our study period and these patients were compared to all the patients who underwent open colorectal surgery in all the units of hospital in the Department of Oncosurgery.

From August 2011 to August 2016, 304 patients with colorectal malignancy undergoing surgery were included in the study, out of which 104 (34\%) underwent laparoscopic procedure and $200(66 \%)$ underwent open surgery.

All patients had endoscopic biopsy proof of cancer. Patient evaluation consisted of history, physical examination followed by routine haematological investigations (Complete haemogram, renal function test, liver function tests) chest $\mathrm{x}$ ray, USG of abdomen, CT scan of abdomen, Colonoscopy, CEA were done to stage the tumour, judge the patient operability, anaesthesia fitness and for appropriate management of patient. All patients for surgery were given bowel preparation starting 1 day before surgery with polyethylene glycol. All patients for surgery were given luminal antibiotics starting 1 day before surgery and IV antibiotic at the time of induction. The standard postoperative care which included antibiotics, IV fluids and chest physiotherapy was provided to all the patients. All the patients were given analgesics on the postoperative day, after that decision for analgesia were based on intensity of pain felt by patient and patients were managed according to WHO criteria of pain management. Routine blood investigations were ordered twice weekly for uncomplicated patients and appropriate corrections were made accordingly (Blood transfusion, albumin, etc.). Details of patients were reviewed from hospital records of surgical, radiotherapy and pathology departments. Once histopathology report was available, standard adjuvant treatment was given according to institute protocol after postoperative recovery. With respect to pathology, patients with invasive cancer were analysed to assess tumour penetration, no. of positive nodes, no. of total nodes dissected in each patient, margins of resection and pathological stage of tumour. For analysis staging was done according to AJCC 7 th ed. ${ }^{5}$ at the conclusion of the study.

Data was collected prospectively and included patient demographics, co-morbidity, tumour site and morphology. Operative information included blood loss and duration of surgery. The complications were documented fully including all unexpected major and minor events. Day on which drain and Ryle's tube was removed was noted. First day of ambulation was noted as the day on which the patient was able to move out of the bed by himself or herself.

\section{RESULTS}

Total 3044 patients observed during this period, divided into 2 groups, Laparoscopic Group (LG) with 104 (34\%) and to Open Colorectal group (OG) with 200 (66\%) patients.

Clinical characteristics are tabulated as below:

\begin{tabular}{|c|c|c|}
\hline $\begin{array}{c}\text { Clinical } \\
\text { Variable }\end{array}$ & $\begin{array}{c}\text { Laparoscopic } \\
\text { Surgery }\end{array}$ & $\begin{array}{c}\text { Open } \\
\text { Surgery }\end{array}$ \\
\cline { 1 - 1 } Gender & $66(63 \%)$ & $104(52 \%)$ \\
\cline { 1 - 1 } Male & $38(37 \%)$ & $96(48 \%)$ \\
\cline { 1 - 1 } Female & & \\
\hline
\end{tabular}

\begin{tabular}{|c|c|c|}
\hline Age (Yrs.) & $55.84(25-76)$ & $55.52(20-81)$ \\
\hline CEA Levels (ng/mL) & 11.24 & 12.12 \\
\hline $\begin{array}{c}\text { No. of Patients } \\
\text { receiving }\end{array}$ & $34(33)$ & $29(56)$ \\
NACT/RT (\%) & & \\
\hline Clinical Stage N & & $40(20)$ \\
(\%) & $22(21)$ & $80(40)$ \\
Stage I & $44(42)$ & $77(38)$ \\
Stage II & $37(36)$ & $3(1.5)$ \\
Stage III & $1(1)$ & \\
Stage IV & \multicolumn{2}{|c}{ Table 1: Demographic Profile of Patients } \\
\hline \multicolumn{2}{|c|}{}
\end{tabular}

In operative findings, there were 12 conversions of laparoscopic to open procedure. Mean operative time was 4.76 (3.5 - 6) hrs. in lap compared to 3.57 (2.5-5) hrs. in open group. Intraoperative blood loss was 352.63 (200$700) \mathrm{mL}$ in lap group vs. 500 (250-800) $\mathrm{mL}$ in open group. Postoperative recovery was studied according to the below mentioned table:

\begin{tabular}{|c|c|c|}
\hline Study Variable & $\begin{array}{c}\text { Laparoscopic } \\
\text { Surgery }\end{array}$ & $\begin{array}{c}\text { Open } \\
\text { Surgery }\end{array}$ \\
\hline Day of Ambulation & & \\
Earliest & 02 & 02 \\
Maximum & 10 & 15 \\
Mean & 4.21 & 5.56 \\
\hline Day of NG Tube Removal & 1 & 2 \\
Earliest & 10 & 7 \\
Maximum & 3.74 & 4.36 \\
Mean & 3 & 3 \\
Day of Analgesia Required & 8 & 7 \\
Minimum & 4.36 & 5.24 \\
\hline Maximum & & \\
Mean & \multicolumn{2}{|c|}{ Table 2: Day of Ambulation } \\
\hline \multicolumn{2}{|c|}{}
\end{tabular}

Complications including mortality and morbidity studied as:

\begin{tabular}{|c|c|c|}
\hline Complication (\%) & Laparoscopic & Open \\
\hline LEAK & $6(5.76)$ & $15(7.5)$ \\
\hline Infective Complication & $7(6.73)$ & $18(9)$ \\
\hline Electrolyte Disturbances & $2(1.92)$ & $3(1.5)$ \\
\hline Death & $1(.96)$ & $3(1.5)$ \\
\hline Obstruction & $7(6.73)$ & $11(5.5)$ \\
\hline Abdominal Burst & $5(4.80)$ & $12(6)$ \\
\hline Resurgery Required & $6(5.76)$ & $14(7)$ \\
\hline \multicolumn{2}{|c|}{ Table 3: Complication in Laparoscopic } \\
and Open Surgery \\
\hline
\end{tabular}

Oncologic adequacy is accessed in terms of free resection margins and lymph node retrieval as per Table 4.

\begin{tabular}{|c|c|c|c|c|}
\hline & $\begin{array}{c}\text { Positive } \\
\text { CRM } \\
\text { (\%) }\end{array}$ & $\begin{array}{c}\text { Positive } \\
\text { Proximal } \\
\text { Margin }\end{array}$ & $\begin{array}{c}\text { Positive } \\
\text { Distal } \\
\text { Margin }\end{array}$ & $\begin{array}{c}\text { No. of Nodes } \\
\text { Retrieved } \\
\text { Mean } \\
\text { (Range) }\end{array}$ \\
\hline Laparoscopic & $7(6.73)$ & 1 & $5(4.80)$ & $8.74(1-26)$ \\
\hline Open & $4(2)$ & 0 & $6(3)$ & $9.64(3-32)$ \\
\hline \multicolumn{5}{|c|}{ Table 4: Oncologic Adequacy } \\
\hline
\end{tabular}




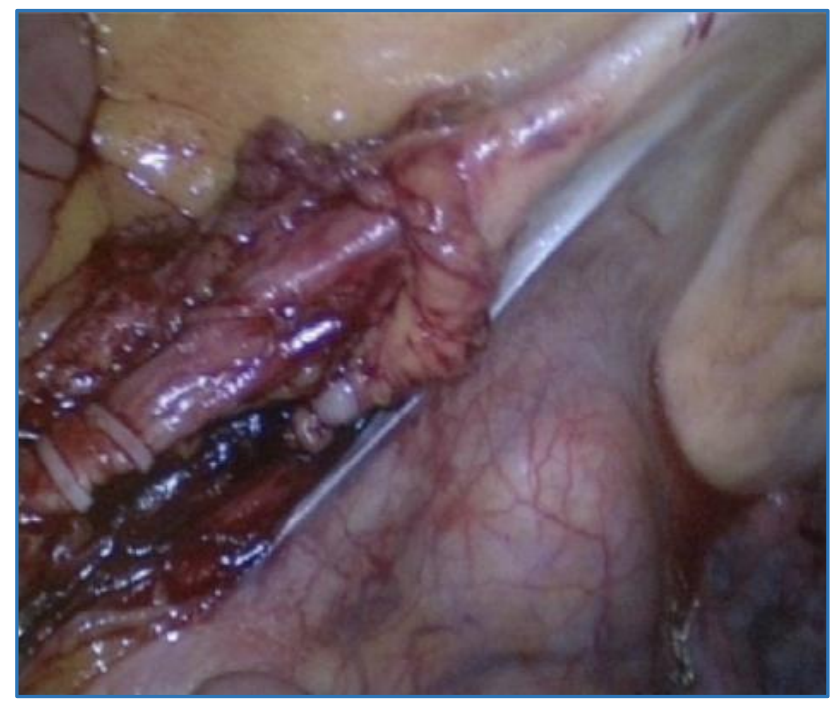

Fig. 1: Picture showing Clips Applied on Inferior Mesenteric Artery Laparoscopic ally

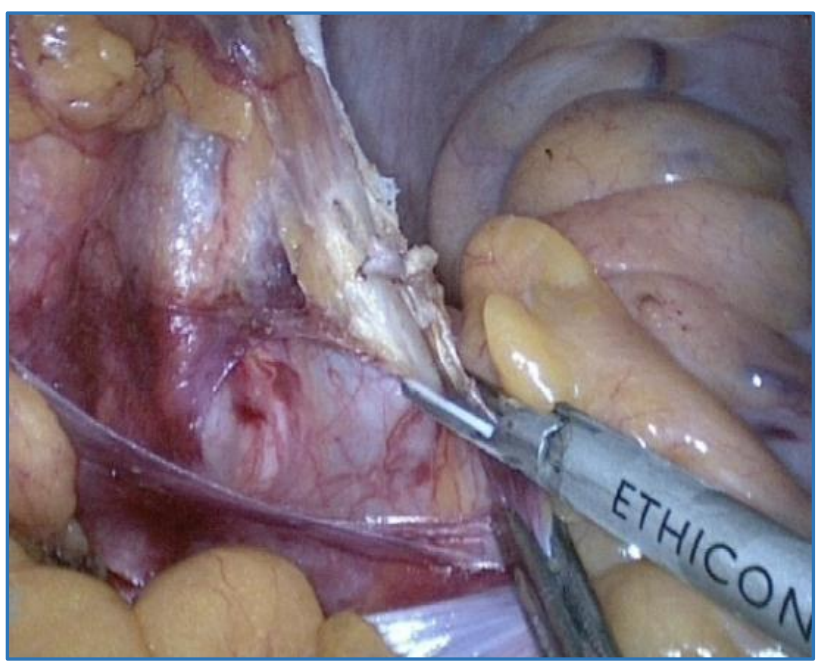

Fig. 2: Picture showing Lateral Pelvic Wall Dissection in a Case of Laparoscopic Low Anterior Resection

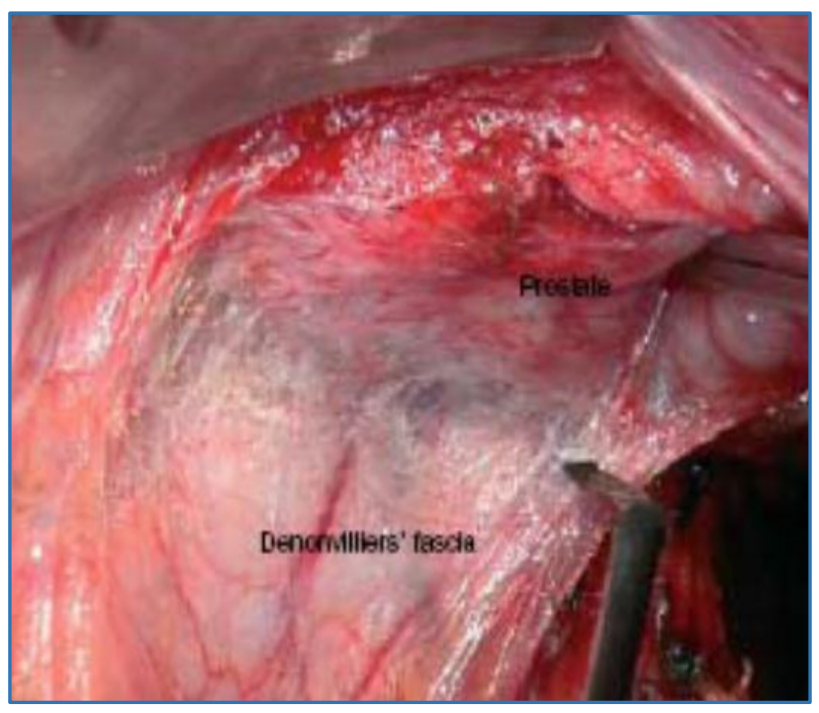

Fig. 3: Picture showing Anterior Dissection during Low Anterior Resection

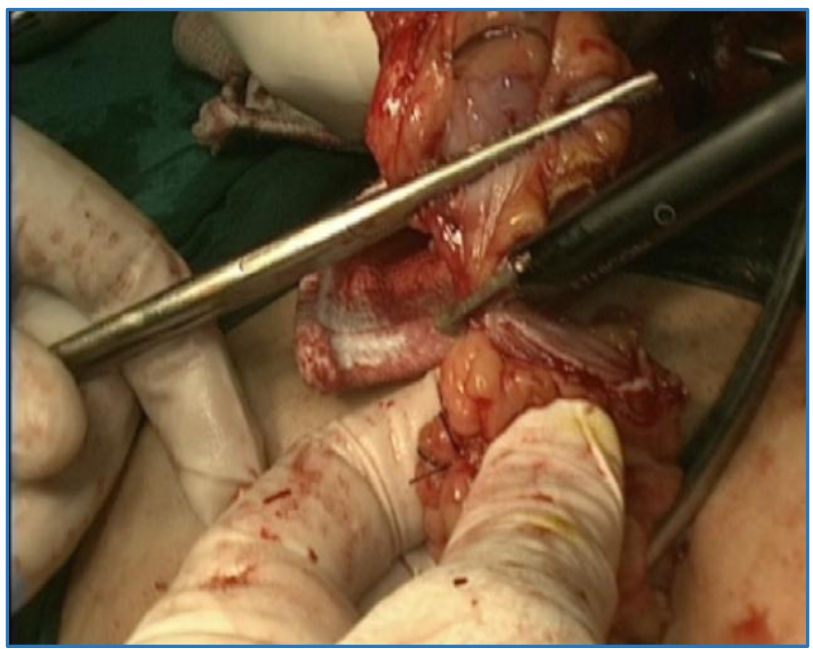

Fig. 4: Picture showing Delivered Colon through a MiniLaparotomy Incision and Dividing it Extracorporeally

\section{DISCUSSION}

Performing laparoscopy for colorectal cancer is technically a relatively straight forward transition for surgeons with advanced laparoscopic skills and familiarity with abdominal anatomy. ${ }^{6}$ It has been demonstrated in the literature that laparoscopic colorectal surgery is safe and feasible with an oncological adequacy comparable to the open approach. But apart from these published data, open surgery is still performed more frequently worldwide. Jacobs et al ${ }^{6}$ reported the first series of laparoscopic colonic resections in 20 patients in $1991 .^{6}$ After this initial study, many other authors have reported on the use of laparoscopic approach for a variety of benign and malignant colorectal conditions.

The first RCT looking at late outcomes of laparoscopic surgery for colonic cancer was reported by Lacey Trials. ${ }^{7}$ Significant advantages were seen with regards to reduced blood loss, early return of intestinal motility, lower overall morbidity and shorter duration of hospital stay in the laparoscopic-assisted group. Also, univariate analysis established a significantly better cancer-related survival in the laparoscopic group, but subgroup analysis stratified for tumour stage revealed that survival benefit was mainly limited to stage III disease. Multivariate analysis demonstrated a better cancer-related survival in the laparoscopic group.

COST (Clinical Outcomes of Surgical Therapy) Study Group trial 8 reported the outcome of 872 patients with colon cancer randomised into two groups (Laparoscopic resection [ $n=435]$ and open resection [ $\mathrm{n}=437])$. The laparoscopic resection group had longer operating times, but quicker recovery and shorter hospital stay. There was no significant difference in morbidity and mortality, tumour recurrence or overall survival. The group concluded: 'it is safe to proceed with laparoscopic resection in patients with cancer.'

The COLOR (Colon Cancer Laparoscopic or Open Resection) Trial $^{9}$ is a multicentre study that included 1248 patients with colon cancer randomised into two groups laparoscopic resection $(n=627)$ and open resection $(n=621)$. The laparoscopic resection group had longer operating times but less blood loss, earlier recovery of bowel function, fewer analgesic requirements and shorter hospital stay. There was no difference in radicality of resection or 28-day morbidity and mortality. The authors concluded: 'laparoscopic surgery 
can be used for safe and radical resection of cancer in the right, left and sigmoid colon.'

The MRC CLASICC (Conventional vs. LaparoscopicAssisted Surgery in Colorectal Cancer) Trial ${ }^{10}$ was done between 1996 and 2002 in 27 UK centres. The study reported a $29 \%$ conversion rate. Patients who had conversion ended up with raised complication rates. Also, there was higher incidence of positive circumferential resection margin after laparoscopic anterior resection, but this did not reach statistical significance. There was no difference in hospital mortality or quality of life at 2 weeks and 3 months postoperatively. The authors concluded: 'laparoscopic resection for colon cancer is as effective as open surgery.' However, impaired short-term outcomes after laparoscopic resection for rectal cancer do not yet justify its routine use.

Abraham et al ${ }^{11}$ reported the outcome of the meta-analysis of RCTs up to 2002. They compared the short-term outcomes of laparoscopic resection and open resection for colorectal cancer. Laparoscopic resection was 30\% longer to perform but had less morbidity, earlier return of bowel function (33\%), reduced analgesia requirements $(37 \%)$ and reduced hospital stay $(20 \%)$. There was no difference in perioperative mortality or oncological clearance. The authors concluded: 'laparoscopic resection for colorectal cancer is associated with better shortterm outcomes without compromising oncological clearance.'

Jayne et al ${ }^{12}$ reported the 3 -year follow-up results for the UK, MRC, CLASICC Trial Group. There was no difference between open and laparoscopic groups in the 3-year overall survival, disease-free survival or local recurrence. The higher positivity of the circumferential resection margin after laparoscopic AR, did not lead to an increased incidence of local recurrence. There was no difference in the quality of life. The authors concluded that: 'long-term outcomes for patients with rectal cancer were similar in those undergoing open surgery and support the continued use of laparoscopic surgery.'

Complete removal of the primary tumour and tumour deposits in the mesentery is the goal of surgery in patients with colorectal cancer. ${ }^{13-14}$ A resection is judged radical when the circumferential, distal and proximal edges of the specimen are devoid of tumour cells.

A major drawback of laparoscopic colorectal surgery is the high cost due to operating room charges. In view of the worldwide increasing concerns over exploding costs in medical care, the decision process for adopting new routine treatments should not only weigh clinical benefits and risks but also consider whether these benefits are worth the health resources used. This decision-making process should be informed by cost-benefit analyses of clinical trials. Recently, Nelson et al ${ }^{15}$ concluded that the results from major trials provide support to conduct comprehensive cost effectiveness analyses of laparoscopic colorectal resection.

Stewart et al ${ }^{15}$ compared laparoscopic with open colorectal resections in 42 and 35 patients, respectively, with a median age of 84 years in each group. Median hospital stay was 9 days for patients having the laparoscopic operation and 17 days in the open cases. At 4 weeks after operation, 30 of the 35 independent patients surviving the operation in the laparoscopic group and 16 of 28 in the open group were back to pre-operative activity levels. They concluded that laparoscopically assisted colorectal surgery was safe and was associated with a low incidence of complications, short hospitalisation and a rapid return to pre-operative activity levels when compared with open colorectal resections in this age group. The feasibility and safety of laparoscopic colorectal resection have been repeatedly reported. The rate of conversion to open surgery is low when strict eligibility criteria are applied and the surgical team is well trained. ${ }^{16}$ The highest conversion rates were reported in series resulting from early experiences. ${ }^{17-18}$

Data from our study indicate that extent of resection including proximal, distal and CRM margins and lymph node examination were similar in both rectal resection groups. The laparoscopic group experienced less pain, shorter hospitalisation and quicker return of bowel function. The wound complication rate was lower in the laparoscopic group; long-term and oncologic outcomes are similar in terms of recurrence and survival. By reducing the operative trauma with laparoscopy, it does not replace important elements of good patient selection, appropriate staging, medical assessment and management in centres that have an ongoing experience of a significant volume of colorectal surgery.

\section{CONCLUSION}

Laparoscopic colorectal surgery results have been shown to be similar in safety and oncological adequacy and completeness of the resection compared to open procedure with benefit of reduction in the morbidity, hospital stay, returns to normal daily activities, lesser blood loss and analgesia requirement. These favourable findings of laparoscopic resection for colorectal malignancy warrant further longer followup and results of prospectively randomised studies. The implementation of laparoscopic colorectal surgery seems inevitable as also consolidated by multiple trials in this regard.

\section{REFERENCES}

1. Siegel R, Naishadham D, Jemal A. Cancer statistics, 2013. CA Cancer Journal Clin 2013;63(1):11-30.

2. Jessup JM, McGinnis LS, Steele GD, et al. The national cancer data base. Report on colon cancer. Cancer 1996;78(4):91826.

3. McKay GD, Morgan MJ, Wong SK, et al. Improved shortterm outcomes of laparoscopic versus open resection for colon and rectal cancer in an area health service: a multicenter study. Diseases Colon Rectum 2012;55(1):4250.

4. Stocchi L, Nelson $\mathrm{H}$. Wound recurrences following laparoscopic assisted colectomy for cancer. Arch Surg 2000;135(8):948-58.

5. Edge S, Byrd DR, Compton CC, et al. AJCC Cancer Staging Manual. 7th edn. 2010;14[1-4].

6. Jacobs M, Verdeja JC, Goldstein HS. Minimally invasive colon resection (laparoscopic colectomy). Surg Laparosc Endosc 1991;1(3):144-50.

7. Lacy AM, Delgado S, Garcia-Valdecasas JC, et al. Port site metastases and recurrence after laparoscopic colectomy. A randomized trial. Surg Endosc 1998;12(8):1039-42.

8. Clinical Outcomes of Surgical Therapy Study Group. A comparison of laparoscopically assisted and open colectomy for colon cancer. $\mathrm{N}$ Engl J Med 2004;350(20):2050-9. 
9. Veldkamp R, Kuhry E, Hop WC, et al. Laparoscopic surgery versus open surgery for colon cancer: short-term outcomes of a randomized trial. Lancet Oncol 2005; 6(7): 477-84.

10. Guillou PJ, Quirke P, Thorpe H, et al. MRCCLASICC Trial Group. Short-term endpoints of conventional versus laparoscopic assisted surgery in patients with colorectal cancer (MRC CLASICC trial): multicentre, randomised controlled trial. Lancet 2005;365(9472):1718-26.

11. Abraham NS, Young JM, Solomon MJ. Meta-analysis of short-term outcomes after laparoscopic resection for colorectal cancer. Br J Surg 2004;91(9):1111-24.

12. Jayne DG, Guillou PJ, Thorpe H, et al. Randomized trial of laparoscopic-assisted resection of colorectal carcinoma: 3-ear results of the UK MRC CLASICC trial group. J Clin Oncol 2007;25(21):3061-8.

13. Heald RJ, Husband EM, Ryall RD. The mesorectum in rectal cancer surgery-the clue to pelvic recurrence? Br J Surg 1982;69(10):613-6.
14. Van de Velde CJH. Total mesorectal excision outcomes-the dutch trial. BCMJ 2003;45(7):314-8.

15. Stewart BT, Stitz RW, Lumley JW. Laparoscopically assisted colorectal surgery in the elderly. Br J Surg 1999;86(7):938-41.

16. Bruch HP, Schiedeck TH, Schwandner O. Laparoscopic colorectal surgery: a five-year experience. Dig Surg 1999;16(1):45-54.

17. Molenaar $\mathrm{CB}$, Bijnen $\mathrm{AB}$, de Ruiter P. Indications for laparoscopic colorectal surgery. Results from the medical centre Alkmaar, the Netherlands. Surg Endosc 1998;12(1):42-5.

18. Delgado F, Bolufer JM, Grau E, et al. Laparoscopic colorectal cancer resection, initial follow-up results. Surg Laparosc Endosc Percutan Tech 1999;9(2):91-8. 